Pathology. 2011;43:58-63. http://dx.doi.org/10.1097/ PAT.0b013e328340e431

8. Rodriguez-Lozano J, Pérez-Llantada E, Agüero J, Rodríguez-Fernández A, Ruiz de Alegria C, Martinez-Martinez L, et al. Sternal wound infection caused by Gordonia bronchialis: identification by MALDI-TOF MS. JMM Case Rep. 2016;3: e005067.

Address for correspondence: Rene Choi, Department of Ophthalmology, Casey Eye Institute, Oregon Health and Science University, 3375 SW Terwilliger Blvd, Portland, OR 97239, USA; email: choir@ohsu.edu

\section{Rickettsiales in Ticks Removed from Outdoor Workers, Southwest Georgia and Northwest Florida, USA}

\author{
Elizabeth R. Gleim, ${ }^{1}$ L. Mike Conner, \\ Galina E. Zemtsova, Michael L. Levin, \\ Pamela Wong, Madeleine A. Pfaff, \\ Michael J. Yabsley
}

\begin{abstract}
Author affiliations: Joseph W. Jones Ecological Research Center at Ichauway, Newton, Georgia, USA (E.R. Gleim, L.M. Conner); Oxford College of Emory University, Oxford, Georgia, USA (E.R. Gleim, P. Wong); University of Georgia, Athens, Georgia, USA (E.R. Gleim, M.A. Pfaff, M.J. Yabsley); Centers for Disease Control and Prevention, Atlanta, Georgia, USA (G.E. Zemtsova, M.L. Levin)

DOI: https://doi.org/10.3201/eid2505.180438
\end{abstract}

We determined the prevalence of selected Rickettsiales in 362 ticks removed from outdoor workers in southwest Georgia and northwest Florida, USA. Persons submitted an average of 1.1 ticks/month. We found Ehrlichia chaffeensis in an Amblyomma maculatum tick, and Panola Mountain Ehrlichia sp. in 2 A. maculatum ticks and 1 Dermacentor variabilis tick.

$\mathrm{T}$ he southeastern United States has multiple tick species that can transmit pathogens to humans. The most common tick species, Amblyomma americanum, is the vector for the causative agents of human ehrlichioses and southern tick-associated rash illness, among others (1). Dermacentor

${ }^{1}$ Current affiliation: Hollins University, Roanoke, Virginia, USA. variabilis ticks can transmit the causative agent of Rocky Mountain spotted fever, and Ixodes scapularis ticks can transmit the causative agents of Lyme disease, babesiosis, and human granulocytic anaplasmosis (1). Although less common in the region, A. maculatum ticks are dominant in specific habitats and can transmit the causative agent of Rickettsia parkeri rickettsiosis (1).

Persons who have occupations that require them to be outside on a regular basis might have a greater risk for acquiring a tickborne disease (2). Although numerous studies have been conducted regarding risks for tickborne diseases among forestry workers in Europe, few studies have been performed in the United States $(2,3)$. The studies that have been conducted in the United States have focused on forestry workers in the northeastern region (2). However, because of variable phenology and densities of ticks, it is useful to evaluate tick activity and pathogen prevalence in various regions and ecosystems.

Burn-tolerant and burn-dependent ecosystems, such as pine (Pinus spp.) and mixed pine forests commonly found in the southeastern United States, have unique tick dynamics compared with those of other habitats (4). The objective of this study was to determine the tick bite risk and tickborne pathogen prevalence in ticks removed from forestry workers working in pine and mixed pine forests in southwest Georgia and northwest Florida, USA.

During June 2009-December 2011, forestry workers in southwestern Georgia (7 counties) and northwestern Florida ( 1 county) submitted ticks crawling on or attached to them. We identified ticks and tested them for selected pathogens (Appendix, https://wwwnc.cdc.gov/EID/ article/25/5/18-0438-App1.pdf). Immature forms of the same species from the same day and person were pooled ( $\leq 5$ nymphs and $\leq 20$ larvae) for testing.

A total of 53 persons submitted 362 ticks (Table). Excluding larvae, the most common tick species submitted was A. maculatum, followed by A. americanum, I. scapularis, and $D$. variabilis. On 4 occasions, 1 person submitted A. tuberculatum ticks ( 3 batches of larvae and 1 batch of nymphs) from a longleaf pine site in Baker County, Georgia. Average submissions per person were 2.6 ticks (median 1 tick), but 1 person submitted 100 ticks. A total of 24 persons submitted ticks more than once, and they submitted an average of 0.08-6.5 ticks/month (overall average submission rate of 1.1 ticks/month). Three ticks were engorged ( 1 D. variabilis adult, $1 \mathrm{~A}$. americanum nymph, and $1 \mathrm{Am}$ blyomma sp. nymph); only the Amblyomma sp. nymph was positive for a pathogen ( $R$. amblyommatis).

Rickettsia spp. prevalence was $36.4 \%$ in adult, $27.9 \%$ in nymphal, and $20 \%$ in larval $A$. americanum ticks; $R$. amblyommatis was the only species identified (Table). Rickettsia spp. were detected in $23 \%$ of $A$. maculatum adults; $R$. amblyommatis was most common (6.0\%), followed by 
Table. Prevalence of Ehrlichia chaffeensis, PME, and Rickettsia spp. in ticks submitted by outdoor workers, southwestern Georgia and northwestern Florida, USA*

\begin{tabular}{|c|c|c|c|c|c|}
\hline \multirow[b]{2}{*}{ Tick species and stage } & \multirow[b]{2}{*}{ Months submitted } & \multicolumn{3}{|c|}{ No. positive ticks/no. tested (\%) } & \multirow[b]{2}{*}{ Rickettsia spp.† } \\
\hline & & E. chaffeensis & PME & Rickettsia spp. & \\
\hline Amblyomma americanum, adults & Feb-Sep & $0 / 11(0)$ & $0 / 11(0)$ & $4 / 11(36.4)$ & 2 R. amblyommatis \\
\hline A. americanum nymphs $\ddagger$ & Mar-Sep & 0/43 (0) & $0 / 43(0)$ & $12 / 43(27.9)$ & 9 R. amblyommatis \\
\hline A. americanum larvae $\ddagger$ & Apr and Oct & $0 / 5(0)$ & $0 / 5(0)$ & $1 / 5(20.0)$ & 1 R.amblyommatis \\
\hline Amblyomma sp. nymphs & Jun and Oct & $0 / 3(0)$ & $0 / 3(0)$ & $1 / 3(33.3)$ & 1 R. amblyommatis§ \\
\hline Amblyomma sp. larvae & Oct & $0 / 5(0)$ & $0 / 5(0)$ & $0 / 5(0)$ & \\
\hline A. maculatum adults & May-Oct & $1 / 83(1.2)$ & $2 / 83(2.4) \pi$ & $18 / 83(21.7)$ & $\begin{array}{c}5 \text { R. amblyommatis, } \S \\
4 \text { R. parkeri,§ } 1 \text { Rickettsia sp. } \\
\text { TR-39/TX125, } 2 \text { Candidatus } \\
\text { R. andeanae }\end{array}$ \\
\hline A. tuberculatum nymphs $\ddagger$ & Apr & $0 / 5(0)$ & $0 / 5(0)$ & $1 / 5(5.0)$ & 1 novel SFG Rickettsia sp. \\
\hline A. tuberculatum larvae & Feb\# & $0 / 182(0)$ & $0 / 182(0)$ & $10 / 182(5.5)^{\star *}$ & 10 novel SFG Rickettsia sp. ** \\
\hline Dermacentor variabilis adults & Jun-Aug & $0 / 10(0)^{\prime}$ & $1 / 10(10.0)$ & $2 / 10(20.0)$ & 1 R. amblyommatis§ \\
\hline Ixodes scapularis adults & Oct-Mar & NT & $0 / 15(0)$ & $7 / 15(46.7)$ & $\begin{array}{l}4 \text { Rickettsia sp. TR-39, } 3 R \text {. } \\
\text { buchneri }\end{array}$ \\
\hline
\end{tabular}

*All Rickettsia spp. were identified by sequencing unless otherwise noted. NT, not tested; PME, Panola Mountain Ehrlichia sp., SFG, spotted fever group. †Rickettsia spp. for whom amplicons did not provide high-quality bidirectional sequences were categorized as unknown Rickettsia spp.

¥Minimum infection prevalence is no. positive tick pools/no. ticks tested.

$\S$ The following $R$. amblyommatis samples were identified by restriction fragment length polymorphism analysis: for $1 D$. variabilis adult, 5 A. maculatum adults, and 1 Amblyomma sp. nymph; for $A$. americanum, 1 adult, 2 nymphs, and 1 larva. Three $A$. maculatum adults were also identified as containing $R$. parkeri positive by restriction fragment length polymorphism analysis.

TData included in Loftis et al. (5).

\#Date was known only for 1 submission of 20 larvae. Dates for others were not provided when submitted.

${ }^{* *}$ Data included in Zemtsova et al. (6).

R. parkeri (4.8\%). A previously detected novel Rickettsia sp. was identified in 10 of $11 \mathrm{~A}$. tuberculatum larval pools and was reported by Zemtsova et al. (6). An additional pool of $A$. tuberculatum nymphs was tested in this study and also was positive for the novel Rickettsia sp. E. chaffeensis was detected in $1 \mathrm{~A}$. maculatum adult (prevalence $1.2 \%$ ), and Panola mountain Ehrlichia sp. was detected in $2 \mathrm{~A}$. maculatum adults (prevalence 2.4\%) and $1 \mathrm{D}$. variabilis adult (prevalence 10\%). No ticks were positive for Borrelia spp., E. ewingii, or Anaplasma phagocytophilum.

Thus, forestry workers were found to encounter ticks on a regular basis, and peak encounter rates reflected previously reported tick seasonality in this region (4). Only $3(0.8 \%)$ of the ticks submitted were engorged, indicating prompt removal of most ticks and thus low risk for pathogen transmission. A. maculatum, a fairly uncommon tick in the southeastern United States, was the most commonly submitted tick. However, A. maculatum ticks dominate in regularly burned pine ecosystems (4), which is where most of these workers spent their time.

We observed several unique findings related to pathogens during this study. Larvae and nymphs of $A$. tuberculatum ticks were submitted on multiple occasions, a tick rarely reported on humans (7). These findings, in conjunction with the identification of a novel Rickettsia sp. (6), suggest that additional research is warranted. This study also identified E. chaffeensis and Panola Mountain Ehrlichia in A. maculatum ticks. Although A. americanum ticks are considered the primary vector of Ehrlichia spp., these pathogens have been occasionally reported in questing A. maculatum ticks, suggesting that this tick might be involved in their transmission cycles $(5,8)$. We also de- tected Panola Mountain Ehrlichia in 1 D. variabilis tick. Thus, further research regarding these alternative tick species as potential vectors of these pathogens is warranted, particularly in the case of $A$. maculatum ticks, which were a common species on forestry workers and are widespread in this region (4).

\section{Acknowledgments}

We thank the persons whom submitted ticks for this study and members of the Yabsley and Levin laboratories for providing laboratory assistance.

This study was supported by the Centers for Disease Control and Prevention/University of Georgia (UGA) collaborative grant (\#8212, Ecosystem Health and Human Health:

Understanding the Ecological Effects of Prescribed Fire Regimes on the Distribution and Population Dynamics of Tick-Borne Zoonoses); the Oxford Research Scholars Program at Oxford College of Emory University; the Joseph W. Jones Ecological Research Center, the Warnell School of Forestry and Natural Resources (UGA); the Southeastern Cooperative Wildlife Disease Study (UGA) through the Federal Aid to Wildlife Restoration Act (50 Statute 917); and Southeastern Cooperative Wildlife Disease Study sponsorship from fish and wildlife agencies of member states.

\section{About the Author}

At the time of this study, Dr. Gleim was a research scientist at the University of Georgia, Athens, GA. She is currently a disease ecologist at Hollins University, Roanoke, VA. Her research interests include wildlife and zoonotic diseases with a particular emphasis on tickborne diseases. 


\section{References}

1. Stromdahl EY, Hickling GJ. Beyond Lyme: aetiology of tick-borne human diseases with emphasis on the south-eastern United States. Zoonoses Public Health. 2012;59(Suppl 2):48-64. http://dx.doi.org/ 10.1111/j.1863-2378.2012.01475.x

2. Covert DJ, Langley RL. Infectious disease occurrence in forestry workers: a systematic review. J Agromed. 2002;8:95-111. http://dx.doi.org/10.1300/J096v08n02_12

3. Lee S, Kakumanu ML, Ponnusamy L, Vaughn M, Funkhouser S, Thornton H, et al. Prevalence of Rickettsiales in ticks removed from the skin of outdoor workers in North Carolina. Parasit Vectors. 2014;7:607. http://dx.doi.org/10.1186/s13071-0140607-2

4. Gleim ER, Conner LM, Berghaus RD, Levin ML, Zemtsova GE, Yabsley MJ. The phenology of ticks and the effects of long-term prescribed burning on tick population dynamics in southwestern Georgia and northwestern Florida. PLoS One. 2014;9:e112174. http://dx.doi.org/10.1371/journal.pone.0112174

5. Loftis AD, Kelly PJ, Paddock CD, Blount K, Johnson JW, Gleim ER, et al. Panola Mountain Ehrlichia in Amblyomma maculatum from the United States and Amblyomma variegatum (Acari: Ixodidae) from the Caribbean and Africa. J Med Entomol. 2016;53:696-8. http://dx.doi.org/10.1093/jme/tjv240

6. Zemtsova GE, Gleim E, Yabsley MJ, Conner LM, Mann T, Brown MD, et al. Detection of a novel spotted fever group Rickettsia in the gophertortoise tick. J Med Entomol. 2012; 49:783-6. http://dx.doi.org/10.1603/ME11264

7. Goddard J. A ten-year study of tick biting in Mississippi: implications for human disease transmission. J Agromed. 2002;8:25-32. http://dx.doi.org/10.1300/J096v08n02_06

8. Allerdice ME, Hecht JA, Karpathy SE, Paddock CD. Evaluation of Gulf Coast ticks (Acari: Ixodidae) for Ehrlichia and Anaplasma species. J Med Entomol. 2017;54:481-4.

Address for correspondence: Elizabeth R. Gleim, Department of Biology and Environmental Studies. Hollins University, 8003 Fishburn Dr, PO Box 9615, Roanoke, VA 24020, USA; email: egleim@hollins.edu

\section{Hepatic Brucelloma Diagnosis and Long-Term Treatment, France}

\section{Marie Amsilli, Olivier Epaulard, Jean-Paul Brion, Patricia Pavese, Christian Letoublon, Isabelle Pelloux, Max Maurin}

Author affiliations: Centre Hospitalier Universitaire de Grenoble, Grenoble, France (M. Amsilli, O. Epaulard, J.-P. Brion, P. Pavese, C. Letoublon, I. Pelloux, M. Maurin); Université Grenoble Alpes, Grenoble (O. Epaulard, C. Letoublon, M. Maurin)

DOI: https://doi.org/10.3201/eid2505.180613
We report a case of hepatic brucelloma in France. This diagnosis may be suspected in any patient who has a liver abscess after traveling to a brucellosis-endemic area. Brucella spp. may be detected by PCR in the liver tissue or suppuration. Abscess drainage and prolonged antimicrobial therapy help achieve healing.

$\mathrm{B}$ rucellosis is a zoonosis found worldwide $(1,2)$ caused by gram-negative, facultative intracellular bacteria of the genus Brucella. Approximately 500,000 new infections are diagnosed annually, mainly in the Mediterranean basin, the Middle East, Latin America, and Asia (1-3). Brucellosis is a rare and mainly imported disease in other countries, including France $(1,4)$. Brucella infection usually occurs after contact with infected animals or consumption of contaminated unpasteurized dairy products. Hepatic brucelloma (HB) is a chronic form of brucellosis arising up to 40 years after initial infection $(1,3,5)$. Only 60 cases $(1 \%-2 \%$ of all brucellosis infections) have been reported in Englishlanguage literature since $1904(1,3,5,6)$. HB is associated with nonspecific systemic clinical symptoms (e.g., fever, malaise, weight loss, upper abdominal pain), moderate biologic abnormalities, and typical hypodense hepatic lesion with peripheral enhancement and central calcification $(1-3,5,6)$.

In April 2015, a previously healthy 55-year-old woman was referred to Grenoble University Hospital after 7 days of fever, asthenia, and weight loss. She had lived in France for 20 years, but had been born in and had traveled every year to Algeria. Her clinical examination was unrevealing. Blood tests showed moderate inflammation and anicteric cholestasis (Table). Hepatic ultrasound (HUS) and computed tomography (CT) confirmed a defect $60 \mathrm{~mm}$ in diameter in liver segments IV and VIII with several subcapsular liquid collections and central calcification (Appendix Figure, panel A, https://wwwnc.cdc.gov/EID/article/25/5/18-0613App1.pdf).

Blood cultures remained sterile. Serologic test results were negative for HIV, amebiasis, and echinococcosis, but positive for Yersinia enterocolitica serotype O:9 and Brucella sp. (Table). HUS-guided drainage of the abscess yielded thick purulent fluid. Fluid cultures were negative, but we detected Brucella melitensis DNA by PCR amplification and sequencing of the $16 \mathrm{~S}$ rRNAencoding gene. Histological findings of liver tissue were compatible with a chronic abscess. We confirmed diagnosis on 2 occasions by PCR detection of Brucella DNA in the liver abscess, as previously reported $(1,3,5-7)$. The serologic profile was suggestive of chronic brucellosis combining low IgM but strong IgG Brucella antibody titers $(1,3,5,7)$. However, Brucella serologic diagnosis is poorly specific, due to antigenic cross-reactions (e.g., 